\title{
How donors choose charities: the role of personal taste and experiences in giving decisions \\ Beth Breeze
}

\begin{abstract}
The question of how donors decide which charities to support, as opposed to questions about whether to give and how much to give, has been under-researched. This article presents findings from a qualitative study of 60 committed donors in the United Kingdom and concludes that charitable decision making is primarily driven by donors' tastes and personal background, and that inertia and path dependency also account for many of their current donation decisions. Despite subscribing to popular beliefs that charitable giving should be directed primarily to the needy, donors often support organisations that promote their own preferences, that help people with whom they feel some affinity and that support causes that relate to their own life experiences.
\end{abstract}

\section{Introduction}

Our understanding of charitable giving in the United Kingdom (UK) is largely dependent on studies that involve counting and measuring properties such as the number of donors and how much they give. This is equally true of charity sector reports such as the annual UK Giving survey (eg, NCVO and CAF, 2012) and government reports such as Helping out and the Community life survey (Cabinet Office, 2007, 2013). While these studies produce extremely important data, and are essential for answering questions about 'how many' and 'how much', they cannot provide insight into the question of 'why'. As Halfpenny (1999:208) has noted, such descriptive statistical exercises reveal little about the 'social reality behind the figures'. This focus on quantitative data gathering is understandable, as there has been an urgent need to comprehend the scale and scope of giving behaviour in the UK and - recently - to monitor changes during a time of public spending cuts. But it has left untouched many important questions about the meanings and motivations behind specific giving decisions, a gap that this article begins to fill.

This gap has been noted before, yet remains inadequately addressed.A decade ago, Bennett (2003: 12) observed that the focus on studying 'the determinant of overall levels of donations to charities' was occurring at the expense of 'why certain individuals choose to give to particular genres of charity', and just two years ago it was suggested that, even in a United States (US) context, 'to date, scholarship on donor choice has been limited' (Barman, 2011: 41). Two papers have usefully examined this question in experimental settings (Bennett, 2003; Bachke et al, 2013: forthcoming), but the 
study reported in this article explores how real donors explain the thinking behind actual giving choices that they have made.

Decision research is a rich vein in the wider literature. A search ${ }^{1}$ of the Web of Knowledge database identifies 7,000 academic articles published on this topic in the last five years (2008-12), and a book summarising the field - Thinking, fast and slow (Kahneman, 2012) - became an international bestseller in 2012. While this topic is currently in vogue, several influential studies of decision making were published in the latter half of the 20th century, and these will be considered further in the discussion section below. However, this body of work focuses on decisions made in the marketplace (such as whether to buy a pension or invest in a new business) or in private settings (such as how to choose a partner or decide who to vote for), rather than on decisions made in a non-profit context, such as which charities to support. This is an extraordinary omission given the prevalence of charitable giving activity across the globe identified in the latest World Giving Index (CAF, 2012), averaging a $30 \%$ participation level across 146 countries, and above two thirds of the population in many countries, including Australia, Ireland, the Netherlands and the UK.

Furthermore, charitable giving decisions ought to be of interest to decision research specialists as they are an archetypical example of difficult choices made under uncertain conditions, given the scale of the choice available and the impossibility of comparing all alternative options. There are over $180,000^{2}$ registered charities in the UK, an estimated 20,000 people employed as professional fundraisers ${ }^{3}$ and many tens of thousands more people who volunteer to ask others to donate money to charity. ${ }^{4}$ This vast range of 'giving opportunities' creates a difficult situation for those willing to donate, as Sargeant and Jay (2004: 261) have noted: 'the sheer number of non-profit organisations that are currently seeking funds can easily confuse even the most diligent of donors'.

Making decisions about which charities to support is therefore a complex problem that has significant consequences for donors, recipients, non-recipients and wider society. Greater insight into the processes behind donors' decision making should increase our understanding of the distribution of charitable donations, and provide guidance on what it might take to change those patterns.

\section{Literature review}

As noted above, the extant research has paid minimal attention to the question of how donors choose charities and focused instead on propensity and level of giving, as related to demographic factors, personality traits, lifestyle factors and attitudinal variables (for multidisciplinary reviews of individual giving research, see Sargeant and Woodliffe, 2007; Bekkers and Wiepking, 2011, 2012).

Research that has explored decision making by donors has tended to focus on a specific cause area, such as the factors that influence decisions to donate to overseas development (Micklewright and Schnepf, 2009) or different disaster appeals (Zagefka et al, 2012), or the role of specific benefits to prompt donor decisions (Sieg and Zhang, 2012). 
Hibbert and Horne make two useful contributions to this debate, firstly by arguing that a better understanding of giving decisions can be achieved by drawing on advances in consumer behaviour research, and then in a later paper presenting empirical evidence to illustrate donors' 'limited problem solving' (Hibbert and Horne, 1995, Hibbert and Horne 1997). An edited volume that presents the results of experimental approaches to understanding charitable giving offers many useful insights into how such decision making occurs, but is primarily focused on giving per se rather than to specific causes or organisations (Oppenheimer and Olivola, 2011). The two chapters of the volume that discuss decision making in relation to specific charities offered participants a restricted list of potential beneficiaries (Cryder and Loewenstein, 2011; Strahilevitz, 2011), whereas the present study imposes no such restrictions.

The one paper that directly refers to the question explored in this article is a study of charitable decision making within UK households, which explores factors behind giving decisions, such as personal contact with a beneficiary, local involvement with a cause and geographical links. The findings are illustrated with qualitative data and the conclusion reached is that giving decisions 'can be quite idiosyncratic ... reflecting people's own interests and concerns' (Burgoyne et al, 2005:395). However, the focus of the paper is on the interaction of individual characteristics and the household economy, and it does not elaborate on the processes involved in making charity choices.

There is, of course, a wide literature on the factors that prompt giving decisions, which identifies the importance of social connections to beneficiaries, involvement in communities of participation and being asked to contribute by an acquaintance (eg, Lohmann, 1992; Radley and Kennedy, 1995; Sokolowski, 1996; Schervish and Havens, 1997). However, this body of work is largely concerned with the extent to which these factors increase or decrease the propensity to give and amounts given, rather than how they translate into specific giving decisions.

Several US studies consider the distribution of philanthropic donations. For example, Ostrower (1995: 36) identifies widespread class-based patterns of giving, such that richer donors support the elite institutions 'around which upper-class life revolves'. Similarly, Odendahl (1990: 3) finds that a prime purpose of the philanthropy of the rich is to perpetuate elite culture because '[e]lite American philanthropy serves the interests of the rich to a greater extent than it does the interests of the poor, disadvantaged or disabled'. However, these studies also focus more on the outcome rather than the process of charitable decision making, and their findings cannot be transferred unproblematically across the Atlantic, given the different historical, cultural and sociopolitical differences between the US and the UK. Indeed, what UK research exists on charitable choices tends to emphasise the importance of the presence of need, and donors' response to that need, as a key factor in giving decisions. A major study of UK public opinion about charities and volunteering, conducted in the early 1990s, concluded that definitions of the purpose of charity and the 'right' recipients of charity are necessarily subjective. However, 'neediness' was identified as a constant defining feature, with those who are needy 'through no fault of their own' (such as people who are sick, children and disaster victims) being viewed as the most appropriate recipients of charitable assistance. While hierarchies of helplessness clearly influence giving decisions, translating judgements about others into concrete 
decisions to allocate money to certain causes and not others was widely viewed as a moral minefield:'The whole idea of choosing between charities is a contentious and morally inflamed area, which immediately resonates with prejudgements of worth and interpretations of need' (Fenton et al, 1993: 25).

Finally, there is a small body of work exploring charitable decision making by very wealthy UK donors (Lloyd, 2004; Breeze, 2012), which risks 'exceptionalising' these decisions, implying that the rich are somehow different from the rest of the population, despite the absence of control groups in such studies.

This article differs from previous studies of giving decisions by presenting data and analysis of the ways that donors of different wealth levels describe the process of making specific decisions about which causes and charities they support. By conducting interviews in which donors have the opportunity to explain their charitable decisions and actions, it seeks to better understand the meanings and motivations involved in their acts of giving. And by investigating the role that need actually plays in giving decisions, it begins to question assumptions behind fundraising practices that treat potential donors as rational agents, rather than social beings situated in contexts that affect their overall charitable outlook as well as their specific charitable decisions.

\section{Methodology}

As the aim of this study was to understand giving decisions, rather than to count them, it used qualitative research methods. Semi-structured interviews with 60 current, committed donors was the data-collection technique chosen as the most suitable to explore how donors decide which charities to support, to discuss their views on the nature and distribution of charitable benefit, and to explore the rationale behind their charitable decisions.

To accommodate a limited research budget, the interviews were conducted by telephone. The interviewees were recruited by the Charities Aid Foundation (CAF), which offers a service for people wishing to create a 'charity bank account' to set aside money specifically for charitable giving. CAF randomly selected 60 charity account holders from its database, filtering by postcode as a method of selecting approximately equal numbers of high-, medium- and lower-income donors. Postcodes are a useful indicative measure of wealth, as they refer to small geographical areas containing property of identifiable value. However, postcode areas may not be homogenous, so to check whether this method achieved the sample distribution that was sought, interviewees were reminded of the national average salary and then asked whether they defined themselves as earning a low, middle or high income. While self-reported income is of unknowable accuracy, responses were used to confirm or dispute their prior categorisation by postcode area, such that they needed to explain that their home was distinctively grander or poorer than their neighbours; this minimised the potential for distortion by a skewed interpretation of their personal financial situation.

The rationale for creating a sample comprising solely CAF account holders, rather than taking a sample of the general population, was that despite most people giving some amount of money to charity in any given four-week period (NCVO and CAF, 2012), there exists a skewed distribution such that total charitable income is reliant 
on the disproportionate generosity of a minority of donors (Clegg et al, 2008: 11; Mohan and Bulloch, 2012). While CAF account holders are not representative of the UK population in terms of income, age or geographical location (they tend to be richer, older and disproportionately from the south-east of England), they are, by definition, proactive and committed donors whose charitable acts are likely to be more typical of those that sustain charities' voluntary income. They were therefore considered the most appropriate people to interview for this study.

Of the 60 interviewees, 22 were women and 38 were men; a third were from the north and two thirds from the south of the UK. There was a spread of ages from people in their thirties to people in their eighties, with more in their sixties than other age groups. The interviews were conducted between January and August 2009, and interview lengths ranged from 10 to 40 minutes, with the average lasting 25 minutes.

The research interviews were approached as 'a conversation with a purpose' (Robson, 1993: 228). A semi-structured format was used, which combined specified questions with the freedom to 'probe beyond the answers ... [to] seek both clarification and elaboration on the answers given' (May, 1997: 111). The interviews comprised open-ended questions about four interrelated topics:

- how the donors define charity;

- their perceptions of the type of people and causes that (a) do benefit and (b) should benefit from charitable activity;

- the basis on which they select charities to receive their donations;

- their experience, as donors, of also being beneficiaries of charitable activity.

The full transcripts of all 60 interviews were analysed using NVivo, a qualitative data analysis computer software package that is particularly suitable for use with rich text-based information. The dataset was inductively analysed, with no preconceived hypotheses in mind, and out of this process 12 key themes emerged. The data were coded to these 12 themes, and during this process it became apparent that there were nine overarching findings, as three of the initial themes were subsumed within related codes. Efforts were undertaken to ensure the reliability of coding decisions through consultations with academic colleagues with expertise in qualitative methods, and minor modifications in coding were subsequently made as a result of their feedback.

When extracts from the interviews are discussed below, the donor's gender, age (by decade, for example 'thirties' or 'sixties') and whether they have a low, middle or high income are indicated in brackets after the quote.

The remainder of this article presents and illustrates nine findings, discusses the data by drawing on theoretical perspectives and ends with some conclusions. 


\section{Findings}

\section{Donors have a broad expectation that charitable activity is related to the meeting of need}

Interviewees expressed a remarkably consistent view that 'needy people' are - and should be - the focus of charitable activity. While conceptions of 'need' were wideranging, many interviewees defined it in terms of financial disadvantage, as this quote shows: "We tend to think of people who are financially stretched" (male, sixties, middle income). Where other types of need arise, such as ill-health, there was an assumption that financial problems would usually also be present in order for the beneficiary to require external assistance: "I would not normally give to people for whom I think other sources were available" (male, eighties, high income). Questions were raised about whether organisations that do not meet needs were to be defined as charities:"I wouldn't give to those other charities - the cacti societies or cricket clubs. I wonder: 'are they really charities?'” (male, thirties, high income).

This finding supports previous research, which concludes that donors have a broad expectation that charities will serve people who are poor (Fenton et al, 1993). However, despite almost unanimous depictions of charity as a vehicle by which people who are better off meet the needs of others, when respondents were asked to describe the causes they actually support and the process of making their giving decisions, it became clear that an assessment of the neediness of prospective beneficiaries was not the sole criterion, and often did not enter into the calculation at all. Before discussing these non-needs-based criteria in more detail, four further findings will be described, which 'set the scene' for understanding the context of donor choice.

\section{Committed donors are not necessarily deliberative donors}

While the sample was composed entirely of people sufficiently committed to charitable giving to have gone to the trouble of setting up a charity bank account, interviewees were often disarmingly honest about their lack of knowledge regarding the causes and charities they support.

Despite distributing thousands of pounds a year, one donor prefaced his replies by saying: "I'm going to be the wrong person to ask because I'm not sure I give it that much intellectual thought" (male, thirties, high income). Others admitted a similar lack of investment in their charitable decision making, as the following quotes illustrate:

'I must admit I don't do a huge amount of research.' (Female, fifties, high income)

'Why did I choose those particular ones? Well, that has been a bit haphazard to be quite honest with you. I mean, I've sort of come across them as I've gone along.' (Male, seventies, high income) 
'I'm not methodical about it ... I don't have any very good way of choosing ... I just go by gut instinct I suppose.' (Male, eighties, mid-low income)

One interviewee claimed to support "basically anything that catches my eye.... It's just what grabs me and what doesn't" (male, fifties, high income). When this donor was asked to explain why he started supporting a particular charity, he replied: "Err, to be honest, I don't know."

Donors often had trouble recalling exactly what it was that they supported and had difficulties remembering the names of recipient causes. One failed to recall the name of his chosen cause, saying: "It's not the Stroke Association but it is a charity that deals with strokes" (male, sixties, middle income). Another struggled to recall the name of one of his recipients: "The hospital for, what do they call themselves? Not disabled, neuro-something disorders [laughs]. It's in Putney" (male, seventies, high income).

As noted above, all 60 interviewees were committed and methodical donors, yet their charitable decision making did not appear to involve much precision, forethought or indeed afterthought.

\section{Donors find it difficult to manage the number of charitable requests they receive}

Many interviewees described the difficulties they encountered when faced with making choices between the many organisations asking for their support:

'I couldn't really have any definite reason for saying "yes" or "no", but you can't support the lot. I stick a pin in.' (Male, seventies, high income)

'I think it all becomes very subjective, doesn't it? I think with those kinds of things, they're not objective choices; they're very subjective [laughs].You can only go by gut feeling I suppose.... It's amazing what comes through the door, and you've got no means of making an objective judgement.' (Female, seventies, middle income)

Methods of coping with the 'bombardment' of requests for support from charitable organisations ranged from the comprehensive to entirely random strategies. As an example of the former, one interviewee explained: "I'm one of those who never turns anything away. I've actually got a box ... everything goes in, in turn, into the box and I give to two a month ... [and] I make sure that everybody gets something over the year" (female, forties, low income). Another described taking a more random approach: "I tend to respond if it comes on my birthday, for instance, or if it comes on my wife's birthday. I say 'well, you're in luck, you're going to get something!"” (male, seventies, high income).

This finding indicates that, to some extent, the distribution of charitable resources is a reflection of the extent of fundraising activities, in particular of direct mail, rather than a reflection of charitable need. It is also clear that even the most committed donors find it difficult to make decisions about their charitable giving. The next two findings concern the strategies that donors use to assist their decision making. 


\section{Self-made classifications and 'mental maps' help some donors to cope with the complexity of the charity sector}

Despite the long-established overarching category of 'charity', many interviewees viewed this as a purely legal or bureaucratic category that was not helpful in informing their own decisions. It was too broad a notion that did not speak to their own understanding of what charity is, or what they wished to achieve with their donations. Instead, donors created their own classifications within the broader concept of 'charity', often involving binary distinctions, as the following quotes illustrate:

'There's two basic categories. There's foreign aid, you know, big, reputable third world development charities.... And the other is charities that work more in Britain. Those are the two main types.' (Female, forties, middle income)

'I've sort of got two distinct categories: [things] to do with being a Christian and what my beliefs are ... [and things] motivated from my pleasures, if you like.' (Female, fifties, middle income)

The two most commonly utilised binary distinctions were: between 'people charities' and 'animal charities'; and between 'domestic charities' and 'international charities'. Interviewees often had a clearly worked-out logic behind their classifications, as the following quotes illustrate:

'My wife and I split them into two groups: ones that we give quite a lot to and ones we give smaller amounts to. The "quite a lot to" are the ones we have been closely associated with, like my college in Cambridge where we support the student hardship fund.' (Male, seventies, high income)

'I've got my "doing good" group, who deliver help to people in need, and those that do "uplifting work", who try to inject something into society like the arts, that's not critical or vital but which nevertheless improves the general state of society.' (Male, sixties, mid-high income)

Others made distinctions in order to decide what they would and would not support, not due to a lack of concern for the latter, but rather to rectify perceived imbalances in popular support for different types of cause:

'I support arthritis research ... a lot of people have a lot of arthritis but it's not as emotive as cancer and things like that, is it?' (Female, eighties, middle income)

'I've got lots of time for medical, educational and so forth. I'm not so excited about environmental and animals - you know, the things that warm the 
cockles of an English person's heart. I'm afraid they don't particularly warm mine.' (Male, sixties, high income)

However, some donors resisted the suggestion that there was any logic or pattern behind their giving decisions. As one interviewee laughingly noted:"You could almost say I'm quite promiscuous I suppose! You'd probably look at my list of charities and find no particular pattern there at all.There's nothing very reasonable or logical about the things I support" (female, fifties, high income).

Where donors did create classifications, it appeared to help them to cope with the complexity of managing their relationship with charitable organisations. But the precise nature of the distinctions drawn by any donor tended to be as idiosyncratic as the conclusions they subsequently drew about which types of charity to support, or not.

\section{Donors use a variety of heuristics, or rules of thumb, to assist their decision making}

Interviewees often described using heuristics (also known as 'rules of thumb') to filter decisions about which causes to support. As defined by Kahneman (2011: 98), heuristics involve replacing difficult questions (such as 'which of the tens of thousands of charities that exist should I support?') with easier questions (such as 'which charity is supported by someone I admire or know well?'). For example, one donor stated that his biggest donation goes to a charity endorsed by a well-known radio news presenter (with whom the donor does not have a personal relationship):

'I think we endow him with a great deal of our personal trust in that he does what he says he's gonna do ... I mean he is somebody who my wife has said if he ever lets us down she'll go round and personally kill him [laughs].' (Male, fifties, high income)

With a similar faith in third-party endorsement, another interviewee admitted that a list of high-profile supporters is a shorthand method of assessing a charity's calibre:

'I often look at who the patrons are, if I like the patrons, if it's somebody who's known in business, it could of course be royalty ... it is a bit of a lazy way of doing things but frankly I have a full-on job and do I want to spend my time looking at accounts? "No" is the answer.' (Female, fifties, high income)

Another heuristic, or short cut to charitable decision-making, involved supporting charities where there existed a personal relationship with those running the organisation, for example where family or friends were staff or trustees. The degree of loyalty to the person asking for funds could also be a useful substitute for making a more difficult call on the "worthiness' of a cause:"I always try and support colleagues and family if they're doing something for sponsorship. I'm not going to say 'oh no, I don't do that"” (female, thirties, middle income). 
Institutional as well as individual ties also influenced giving decisions. Notably, church-going donors often supported charities chosen by their congregation, as one donor explained: "We've also got a link, the church, with a parish in Zimbabwe, so we support that" (male, seventies, high income).

Geographical connections also helped to circumscribe giving decision, as one donor explained:"I think people do relate more locally. There are hospices everywhere but somehow in your own backyard you can relate to it. Like in football, generally you support your local team" (male, forties, high income)

Giving in the vicinity of where one lived was also linked to the desire to support charities that were perceived to be competent in making efficient use of donations, as this interviewee explained:"We know what goes on locally so we know how efficient it is, whereas a lot of these other people who send you things through the post, we haven't a clue what they're up to" (male, sixties, middle income).

Ties of individual and institutional loyalty, respect for loved ones' wishes and geographical connections are all useful 'short cuts' for distinguishing which requests for donations should get a positive response. No doubt many other heuristics are also apparent in donors' giving decisions. The next finding demonstrates another version of 'short-cut' decision making, whereby donors automatically include or exclude certain causes.

\section{Donors perceive some causes as automatically deserving or undeserving of support}

Many interviewees were keen to name the types of causes they would refuse to support, despite that question not being explicitly asked. Having volunteered the causes they excluded, they almost always went on to justify that refusal, for example: "There are no animal charities [on our list]. We're not cruel to animals, but we're neither of us great animal lovers ... animals take second place to humans and other important causes for us" (female, fifties, high income). Another interviewee described the opposed scenario: "It's not that I dislike people but I'm a great animal lover, a great wildlife lover, so I donate to things like the local wildlife rescue centre and the Dogs Trust... That's slightly less altruistic in a way because I just love animals [laughs]" (female, fifties, high income).

Excluding certain types of cause in order to make decision making more manageable was an explicit rationale in some cases: "I exclude all animal charities, not because I'm unsympathetic to them but partly to narrow the field" (male, eighties, mid-low income). While donors were often keen to name the causes they did not approve of or support, 'not approving' and 'not supporting' were not always one and the same category. For example, one respondent said:"I would rather see that resource directed more broadly to those who have greater need ... [so] I have reservations about arts and cultural charities, although I am a member of one" (male, sixties, middle income).

This gap between an expressed position (in this case, that arts and cultural charities do not serve the most needy and are therefore not the most appropriate beneficiaries) and actual behaviour (the donor still supports an arts and cultural charity) is at the heart of the problem in understanding the decision making of donors, just as it is in the study of decision making more widely. 
The final three findings concern the non-needs-based criteria that were found most commonly to lie behind donors' decision making.

\section{Donor taste is a dominant factor in the selection of charitable recipients}

The personal taste of donors was found to be the most salient factor in the selection of charitable beneficiaries. Respondents typically reported supporting "things that happen to appeal to me", causes that are "close to my heart", things that "touch a chord" and charities "that I admire" and "am comfortable giving to". This approach might collectively be termed 'taste-based giving', as opposed to 'needs-based giving', and donors' rationales for taking the former approach are illustrated in the following quotes:

'It's really what in one's own mind one thinks is a deserving cause, and it does range, you know, hugely widely, and totally irrationally. I mean, I would support deserving dogs but I wouldn't support cats [laughs] because I just happen not to like cats. It's as silly and as simple as that.' (Male, seventies, high income)

'I donate to the RSPB [Royal Society for the Protection of Birds] because bird-watching is one of my great obsessions. It's my, kind of, my treat to myself, if you like.' (Male, fifties, middle income)

'[I support] Sustrans because we're interested in cycling and we live near a Sustrans route ... Ramblers [Association] sometimes, because we like walking ... the RSPB because we like bird-watching.' (Female, seventies, middle income)

'I'm a passionate skier, so a personal favourite is a charity that provides snow sports opportunities for people with disabilities.' (Male, sixties, middle income)

Taste and personal preferences appeared to be factors in giving decisions even when donors perceived themselves as motivated by needs. Examples of the discrepancy between theory and practice include a donor who defined the appropriate beneficiaries of charity as "people in hunger or poverty or ill-health", and yet went on to describe the focus of his support as environmental issues because "we like the countryside, I suppose" (male, seventies, high income). Another interviewee described appropriate beneficiaries as "people who are hard up in this country and people who are hard up abroad", but explained that he supports steam railway restoration projects, because:

'I think it's sort of worthwhile from the point of view of society, I feel it's worth keeping them going as sort of something this country has been able to do in the past and is still quite good at doing now ... [so] I did put a rather large sum of money into helping to buy an oldVictorian steam engine ... I 
hope maybe when it gets going I might be allowed to stand on the footplate and blow the whistle [laughs].' (Male, seventies, high income)

Tastes are acquired as a result of an individual's socialisation and lifelong experiences, which includes their upbringing and family, their participation in educational and work institutions, and their interactions with friends, peers and colleagues. The next finding focuses on how these factors affect their choice of charitable recipients.

\section{Personal background influences donors' selection of charitable recipients}

In addition to taste, donors' personal background is the other key non-needs-based criterion behind charitable giving decisions. An individual's charitable outlook is acquired as a result of lifelong processes, and specific charitable giving decisions are often closely related to earlier life experiences. Examples of autobiographical factors behind giving decisions came up frequently in the interviews, for example:

'I have a child and the very first thing I started off doing was child sponsorship.' (Female, forties, high income)

'My brother died of bowel cancer so I give to cancer research.' (Male, thirties, high income)

'A number of my friends have died of cancer and they've had enormous help from Marie Curie, so I would definitely respond to them.' (Male, seventies, high income)

'We've got one or two friends who've had multiple sclerosis so we signed up for the MS Society.' (Male, fifties, high income)

'I support the British Heart Foundation since I had a quadruple bypass myself.' (Male, seventies, high income)

Many interviewees made explicit the connection between experiences in their own lives and subsequent decisions to donate:

'My mother became disabled and needed wheelchairs and things like that, and I realised what a difference it made, so I've been keen to give to charities that provide wheelchairs in the third world.' (Female, sixties, mid-high income)

'My wife is blind, she does have a guide dog for instance and she gets a range of support from the Royal Institute for the Blind. I wouldn't say we wouldn't have supported blind charities if she wasn't, but obviously that gives us a particular interest in that.' (Male, sixties, high income) 
'[I support] butterfly conservation. When I was a boy I collected butterflies and I'm trying to give back, if you like, the damage that I did so to speak. In those days you were encouraged to kill butterflies and collect them, so that's an important one.' (Male, seventies, middle income)

Personal connections can also inspire donations with the hope of bringing benefits in the future, rather than 'repaying' benefits received in the past:

'I sail quite a lot. I've never had to be rescued but I give the lifeboats some money every year and I see that as being, the return I get on that, being like an insurance policy. I know that the lifeboats will rescue people regardless of whether they've paid their membership subs, but I see that as an intangible benefit.' (Male, thirties, middle income)

Another interviewee explained:

'There's a lot of arthritis and rheumatism in my family. I'm kind of figuring that I may get some benefit in the future from the research that I'm funding now ... I'm thinking: "well, I'll give them some money and with a bit of luck they'll have sorted something out!"' (Female, fifties, low income)

Changes in giving decisions were also related to changes in life experiences: "My original objective was to try and make the world slightly better, so [I supported] what seemed to be the big issues, like deforestation ... but now I've got ageing parents so I'm more interested in, like, cancer support" (male, forties, high income). The autobiographical connection between a donor and a cause can introduce some unusual charities into a donor's portfolio, as this interviewee explained: "My dad died unexpectedly, and mountain rescue was involved in him being brought down from the mountain, so I've given quite often to mountain rescue. It doesn't fit with my general themes but that's why. There's a personal connection" (female, thirties, middle income).

It would be wrong to suggest that charitable behaviour is determined entirely by personal background, as interviewees also noted personal connections that did not result in donations, such as loved ones dying from diseases or in hospices, which they did not go on to support. However, the data demonstrate that people frequently draw on their own life experiences when making giving decisions.

\section{Inertia and path dependency influence current giving decisions}

While interviewees offered many positive explanations for their giving decisions, related to personal taste and experiences, they also noted that some of their donations went to charities they had selected for some reason in the past and had simply never revisited or revoked that earlier decision. Despite historic commitments impeding their ability to take on causes that might be preferable, donors rarely took the time to revise the distribution of their donations and shake out the old to make way for the new. 
'I very rarely look at a new charity' (Female, fifties, high income)

'I'm afraid what I do now is say I've selected the charities to which I'm contributing, and I'm not adding to my list.' (Female, seventies, middle income)

'It is very rare that I give money to anybody new. Because otherwise, you know, the amount can increase exponentially, so one has to have a limit.' (Male, sixties, mid-high income)

Rather, donors generally built upon past decisions, making incremental changes, perhaps adding a new recipient that fitted within pre-existing categories that were mentally 'approved', as this interviewee illustrates: "We tend to really, having made the decision, we more or less keep the same ones going, rather than chop and change each year" (male, seventies, high income). Such inertia exists despite an awareness that it does not result in optimal decisions for either the donor or the charity sector, as the following two quotes illustrate:

'I have a list, which I keep fairly methodically so as to donate once a year and there are items on that list which probably shouldn't really be there, but perhaps through laziness remain.' (Male, eighties, mid-low income)

'There comes a point where you get endless letters from charities and you think, "yes, they do need help: blind people need help, cancer people need help", but you have to draw a line and you have to say, "I'm awfully sorry but I've got my list ... these things seem to be the ones we've come across and we've had no reason to stop supporting them" (Female, seventies, middle income)

The concept of 'path dependency' refers to the fact that decisions taken in the present are limited by decisions made in the past, even though past circumstances may no longer be relevant. One reason donors feel unable to alter previous giving decisions appears to be the emotional weight of revoking support for a charity: "One problem with giving to charity is that once you start then it's difficult to stop. I'm less enthusiastic [about supporting some of my charities] but one feels obliged to do it again" (male, sixties, mid-high income).

Inertia and path dependency may be useful to those charities that continue to benefit from past giving decisions. However, the fact that some donors persevere with their little-understood list of recipients and anticipate guilt if they were to change tack, is likely to create barriers to broadening their giving.

\section{Discussion}

As noted in the Introduction, there is a growing body of work contesting the long-held assumption that decision making is largely a deliberate, logical and rational activity. 
The findings presented above reinforce the suggestion that normative assumptions about rational choice do not provide an adequate descriptive model of decision making by charitable donors. However, while decision research is currently in vogue for behavioural economists, it has been prefigured by at least three substantive contributions that are all helpful in discussing the findings set out above.

Over half a century ago, Lindblom (1959) examined the approaches that public policy analysts took to solving complex problems and concluded that, despite expectations of highly systematic methods, it was more accurately depicted as 'the science of muddling through'. Evaluating all possible options was found to be impossible due to the excessive costs in terms of time and money and because it 'assumes intellectual capacities and sources of information that men simply do not possess' (1959: 80). Lindblom identified a process of 'incrementalism', which involves restricting potential options to only those that differ in a small degree from previous decisions such that decision makers are "continually building out from the current situation, step-by-step and by small degrees' (1959: 81). This description is in line with situations described above where donors keep - and occasionally tweak - their lists of recipients in line with their previous choices.

This model of decision making acknowledges that people do not attempt to make the best decisions; rather, they have the distinctly less ambitious goal of making better decisions. While the example in the Lindblom study concerns public policy analysts, the theory is applicable to other decision-making scenarios, such as charitable giving decisions, because:

The same model is inevitably resorted to in personal problem solving, where means and ends are impossible to separate, where aspirations or objectives undergo constant development, and where drastic simplification of the complexity of the real world is urgent if problems are to be solved in the time that can be given to them. (1959: 88)

Revisiting this theory in a later paper, Lindblom (1979) stated we must 'muddle through' because we are simply unable to achieve intellectual mastery of complex social problems: 'No person, committee, or research team, even with all the resources of modern electronic computation, can complete the analysis of a complex problem. Too many interacting values are at stake, too many possible alternatives' (1979: 518). This is a plausible description of the situation facing donors who are willing to give and keen to make good choices but lack the resources and ability to make the 'best' choice. They must therefore use other strategies, such as using heuristics, pursuing their personal tastes, drawing on their life experiences and building on their previous giving decisions.

Simon's (1981) concept of 'bounded rationality' is in the same mould of 'less heroic' decision making as that described by Lindblom, but Simon also noted that individual rationality is limited by the finite amount of information we possess, the cognitive limitations of our minds and the amount of time we are willing and able to devote to making decisions. He argued that in the absence of the resources and abilities to make fully rational decisions, we must instead accept the limits of our bounded 
rationality and seek satisfactory, rather than optimal, solutions. The need to pursue decision-making strategies based on adequacy rather than on optimisation (which Simon called 'satisficing') is driven not only by the finite nature of resources, time and information, but also by the fact that decision making involves a mixture of the partial information that individuals possess and the values and preferences they hold at any given time.

Simon suggested that individuals operating under conditions of bounded rationality use heuristics to guide their decision making, with a notable reliance on the influence of authority and ties of loyalty. The data presented in this article provide support for Simon's argument, as donors reported using such techniques to filter decisions about which causes and charities to support.

The third theoretical approach that is useful in understanding the findings of this study is Douglas's (1997) concept of 'cultural refusal', which refers to the fact that people do not pay attention to, or even notice, options that are culturally alien to them. Cultural refusal involves screening out certain goods or services that are incompatible with an individual's identity. For example, working-class donors may not countenance support for organisations that promote cultural activities that they perceive as relevant only to other classes, such as opera or ballet. They 'refuse' such causes because they are incongruous with their identity. The existence of 'automatic exclusions' described in this article also supports Douglas's (1997: xx) claim that 'people do not know what they want, but they are very clear about what they do not want'. This point is illustrated by interviewees in the present study who, despite not being asked about the causes they refused to support, were keen to put those categories they excluded on record - for example: "I don't do animals" and "I never support organisations working abroad".

Refusing to even consider whole swathes of the charity sector is one strategy for making decision making more manageable, but it may result in less optimal giving choices as the 'refused' organisations may have been more effective in supporting needs or more enjoyable to support.

The theoretical concepts of 'incrementalism', 'bounded rationality' and 'cultural refusal' help to bring analytical clarity to the data. They highlight that all types of decision making involve complex choices and processes, such that individuals must develop strategies to cope with the complexities and reach conclusions despite the ever-present limitations of information, cognitive ability and time.

Viewing the data through these theoretical lenses also highlights some important insights into how donors choose charities. First, it may be necessary to adjust expectations regarding people's capacities - and willingness - to process information about charitable beneficiaries, such that more detailed metrics on charitable activity and impact may be less well received by potential donors than anticipated. Second, appeals to potential donors should reflect the widespread use of heuristics, such as ties of loyalty and third-party endorsements, and not assume that charitable decision making relies on fully reasoned arguments for prioritising a particular concern. Third, it is important to recognise that donors are social beings, and that their socially embedded rationalities may well differ significantly from dominant fundraiser rationalities, resulting in appeals that focus on beneficiary needs to the exclusion of 
donor tastes. The growing literature challenging assumptions made by marketers that their consumers are predominantly rational, and demonstrating that social settings and emotions play an important role in decision making, has not yet made its way fully into the non-profit sector.

However, it is important to emphasise potential limitations in the data and analysis presented in this article. As noted in the methodology section, the 60 interviewees were drawn from a pool of committed donors who are richer and older than average, which may affect their approach to charitable decision making. It is possible that younger or less wealthy supporters use different logics to make decisions and this would be a useful avenue for future research to explore.

\section{Conclusion}

Despite popular beliefs that charitable giving should be directed primarily to those who are needy, donors often support organisations that promote their own preferences, that help people they feel some affinity with, and that support causes that relate to their own life experiences.

The finding of an apparent lack of rigour in making decisions about charitable donations has implications for both policy and practice, and requires further exploration and explanation. Giving is often assumed to be an important aspect of life for many donors and the total sums donated are substantial - $\& 9.3$ billion in the UK in 2011/12 (NCVO and CAF,2012). If even committed donors are not especially thoughtful in distributing their donations, as this article suggests, this has implications for the current debate around providing greater information in order to help donors to make better decisions. Interviewees were quite relaxed about acknowledging their lack of rigour in choosing between different charities and charitable causes, and it may be the case that many donors are content to 'muddle through' and will not avail themselves of new information that becomes available.

Studies of the wealthiest givers have long noted that philanthropic gifts 'are very much matters of personal commitment, taste and identification' (Silber, 1998:141-2). The data presented in this article demonstrate that donors of all wealth levels seek to maximise their personal satisfaction, rather than seek optimum outcomes from a broader societal perspective: they simplify their decision making by categorising charities into broad groups and by deploying heuristics, they align their charitable giving with their interests and they use their donations to pursue their passions, preferences and personal involvement.

Given the voluntary nature of charitable activity, this is not a surprising conclusion. Giving and philanthropy have always been as much supply led as demand driven: the freedom to distribute as much as one wants to whom one chooses is what distinguishes giving from paying tax. Yet the methods used to encourage donations tend to assume that philanthropy depends on objective assessments of need rather than on donors' enthusiasms. The tendency to overestimate the extent to which people act as rational agents results in fundraising that tends to focus on the dimensions and urgency of the problem for which funding is sought. The assumption underlying this approach is that donations are distributed in relation to evidence of neediness, 
when the findings of this study reveal that much giving could be described as 'taste based' rather than 'needs based'.

This article has attempted to shed light on the processes by which donors choose which charities to support. The findings illustrate that making choices between competing charitable causes and organisations is a complex matter. There is widespread acknowledgement that choices are inevitably based on inadequate information, as the vast number of options makes it impossible to rationally assess them all. As has been noted by US philanthropy advisers: 'All stars in the galaxy of non-profit ideas are never under full consideration' (Bronfman and Solomon, 2010: 77).

This study shows that UK donors use several strategies to limit the number of 'stars' under consideration and achieve a more manageable decision-making process. Donors:

- create mental classifications of the types of charities that they will and will not countenance supporting;

- rely on their personal tastes and preferences;

- $\quad$ are influenced by their own personal background and trust in maintaining their own historic giving decisions.

Implementation of these strategies occurs to a varying degree and with varying emphasis by donors, each of whom has their own personal views, acquired as a result of lifelong processes of socialisation, as to the nature and purpose of charitable activity and their own ambitions for what they hope to achieve through their giving. The end result is the personal 'filtering' of an unmanageable number of options down to the list of charities that each donor chooses to support.

\section{Notes}

${ }^{1}$ This search was conducted on 10 February 2013.

${ }^{2}$ According to the Charity Commission website (www.charity-commission.gov.uk/) in May 2013, there are 163,163 'main charities' and a further 17,128 'linked charities' on the Register of Charities, making a total of 180,291 registered charities.

${ }^{3}$ The most recent figure relating to the size of the fundraising profession was published in Charity trends 2007 (CAF, 2007: 181), which states that in 2005/06, 24,960 people were employed in fundraising and administrative roles within the top 500 charities.

${ }^{4}$ A report by the Cabinet Office (2007: 28) - Helping out: A national survey of volunteering and charitable giving - found that the most common form of volunteering, undertaken by $65 \%$ of volunteers, was 'raising or handling money'.

\section{References}

Bachke, M.E., Alfnes, F. and Wik, M. (2013 forthcoming; online first since January 2013 DOI 10.1007/s11266-012-9347-0) 'Eliciting donor preferences', Voluntas [online first].

Barman, E. (2011) 'With strings attached: nonprofits and the adoption of donor choice', Nonprofit and Voluntary Sector Quarterly, 37 (1): 39-56.

Bekkers, R. and Wiepking, P. (2011) 'Who gives? A literature review of predictors of charitable giving. Part One: Religion, education, age and socialisation', Voluntary Sector Review, 2 (3): 337-65. 
Bekkers, R. and Wiepking, P. (2012) 'Who gives? A literature review of predictors of charitable giving. Part Two: Gender, family composition and income', Voluntary Sector Review, 3 (2): 217-45.

Bennett, R. (2003) 'Factors underlying the inclination to donate to particular types of charity', International Journal of Nonprofit and Voluntary Sector Marketing, 8 (1): 12-29.

Breeze, B. (2012) Coutts million pound donors report, London: Coutts and University of Kent.

Bronfman, C. and Solomon, J. (2010) The art of giving: Where the soul meets a business plan, San Francisco, CA: Jossey-Bass.

Burgoyne, C.B., Young, B. and Walker, C.M. (2005) 'Deciding to give to charity: a focus group study in the context of the household economy', Journal of Community and Applied Social Psychology, 15 (5): 383-404.

Cabinet Office (2007) Helping out: A national survey of volunteering and charitable giving, London: Cabinet Office.

Cabinet Office (2013) Community life survey: Q2 2012-13, London: Cabinet Office.

CAF (Charities Aid Foundation) (2007) Charity trends 2007, London: CAF.

CAF (2012) World Giving Index, London: CAF.

Clegg, S., Goodey, L., Walls, P. and Wilding, K. (2008) UK giving 2008, London: Charities Aid Foundation and National Council for Voluntary Organisations.

Cryder, C. and Loewenstein, G. (2011) 'The critical link between tangibility and generosity', in D.M. Oppenheimer and C. Olivola (eds) The science of giving: Experimental approaches to the study of charity, New York, NY:Taylor and Francis.

Douglas, M. (1997) 'In defence of shopping', in P. Falk and C. Campbell (eds) The shopping experience, London: Sage Publications.

Fenton, N., Golding, P. and Radley, A. (1993) Charities, media and public opinion, Loughborough: Department of Social Sciences, University of Loughborough.

Halfpenny, P. (1999) 'Economic and sociological theories of individual charitable giving: complementary or contradictory?', Voluntas, 10 (3): 197-216.

Hibbert, S. and Horne, S. (1995) 'To give or not to give: is that the question?', European Advances in Consumer Research, 2: 179-82.

Hibbert, S.A. and Horne, S. (1997) 'Donation dilemmas: a consumer behaviour perspective', Journal of Nonprofit and Voluntary Sector Marketing, vol 2, no 3, pp 261274.

Kahneman, D. (2011) Thinking, fast and slow, London: Penguin.

Lindblom, C. (1959) 'The science of muddling through', Public Administration Review, 6: 79-88.

Lindblom, C. (1979) 'Still muddling, not yet through', Public Administration Review, 39: 517-26.

Lloyd, T. (2004) Why rich people give, London: Association of Charitable Foundations.

Lohmann, R. (1992) 'The commons: a multidisciplinary approach to nonprofit organisation, voluntary action and philanthropy', Nonprofit and Voluntary Sector Quarterly, 21 (3): 309-24.

May,T. (1997) Social research: Issues, methods and process, Buckingham: Open University Press. 
Micklewright, J. and Schnepf, S. (2009) 'Who gives charitable donations for overseas development?', Journal of Social Policy, 38 (2): 317-41.

Mohan, J. and Bulloch, S. (2012) The idea of a 'civic core': What are the overlaps between charitable giving, volunteering and civic participation in England and Wales?,TSRC working paper 73, Birmingham:Third Sector Research Centre, University of Birmingham.

$\mathrm{NCVO}$ and CAF (National Council for Voluntary Organisations and Charities Aid Foundation) (2012) UK giving 2012: An overview of charitable giving in the UK, 2011/12, London: CAF.

Odendahl, T. (1990) Charity begins at home: Generosity and self-interest among the philanthropic elite, New York, NY: Basic Books.

Oppenheimer, D.M. and Olivola, C. (eds) (2011) The science of giving: Experimental approaches to the study of charity, New York, NY: Taylor and Francis.

Ostrower, F. (1995) Why the wealthy give: The culture of elite philanthropy, Princeton, NJ: Princeton University Press.

Radley, A. and Kennedy, M. (1995) 'Charitable giving by individuals: a study of attitudes and practices', Human Relations, 48: 685-709.

Robson, C. (1993) Real world research: A resource for social scientists and practitionerresearchers, Oxford: Blackwell.

Sargeant, A. and Jay, E. (2004) Fundraising management, London: Routledge.

Sargeant, A. and Woodliffe, L. (2007) 'Individual giving behaviour: a multidisciplinary review', in A. Sargeant and W. Wymer (eds) The Routledge companion to nonprofit marketing, London: Routledge.

Schervish, P. and Havens, J. (1997) 'Social participation and charitable giving: a multivariate analysis', Voluntas, 8 (3): 235-60.

Sieg, H. and Zhang, J. (2012) 'The effectiveness of private benefits in fundraising of local charities', International Economic Review, 53 (2): 349-74.

Silber, I. (1998) 'Modern philanthropy: reassessing the viability of a maussian perspective', in N.Allen and W.J.Allen (eds) Marcell Mauss today, Oxford and New York, NY: Berghahn.

Simon, H. (1981) Models of bounded rationality: Volume 1: Economic analysis and public policy, Boston, MA: MIT Press.

Sokolowski, S. (1996) 'Show me the way to the next worthy deed: towards a microstructural theory of giving and volunteering', Voluntas, 7 (3): 259-78.

Strahilevitz, M.A. (2011) 'A model of the value of giving to others compared to the value of having more for oneself: implications for fundraisers seeking to maximise donor satisfaction', in D.M. Oppenheimer and C. Olivola (eds) The science of giving: Experimental approaches to the study of charity, New York, NY: Taylor and Francis.

Zagefka, H., Noor, M. and Brown, R. (2012) 'Eliciting donations to disaster victims: psychological considerations', Asian Journal of Social Psychology, 15 (4): 221-30.

\section{Beth Breeze}

School of Social Policy, Sociology and Social Research

University of Kent, Canterbury, UK

B.Breeze@kent.ac.uk 